\title{
Ficciones seriadas en televisión: aproximación cuantitativa y cualitativa al consumo de los estudiantes de Comunicación Audiovisual. El caso español ${ }^{1}$
}

\section{Mar Chicharro Merayo²}

Recibido: 2016-01-17

Enviado a pares: 2016-01-17
Aprobado por pares: 2016-02-01

Aceptado: 2016-02-10

DOI: 10.5294/pacla.2017.20.1.6

Para citar este artículo / to reference this article / para citar este artigo

Chicharro Merayo, M. (2017). Ficciones seriadas en televisión: aproximación cuantitativa y cualitativa al consumo de los estudiantes de Comunicación Audiovisual. El caso español. Palabra Clave, 20(1), 116-141. D0I: 10.5294/pacla.2017.20.1.6

\section{Resumen}

El presente trabajo reflexiona sobre la relación entre jóvenes y ficción televisiva contemporánea. Más concretamente, analiza las tendencias en el consumo de los estudiantes del Grado en Comunicación Audiovisual en España. Se parte del supuesto de la existencia de una subcultura juvenil, en la que las prácticas de ocio hacen las veces de variable de pertenencia. Los estudiantes de Comunicación Audiovisual, en especial, orientados hacia el seguimiento de estos productos, son presentados como un grupo que hace de sus usos y consumos de teleseries una seña de identidad y distinción tanto en su dimensión cuantitativa (tiempos y productos) como en

1 El presente trabajo se inserta en los siguientes proyectos/grupos de investigación: Cultura audiovisual y representaciones de género en España: mensajes, consumo y apropiación juvenil de la ficción televisiva y los videojuegos, ref. FEM 2011-27381, Ministerio de Economía y Competitividad, España. Grupo de Investigación Complutense Historia y Estructura de la Comunicación y el Entretenimiento, ref. 940439, Gr 58/08, España. Historia de la programación y de los programas de televisión en España (cadenas de ámbito estatal): de la desregulación al apagón analógico (1990-2010), ref. CSO2015-66260-C4-1-P, Ministerio de Economía y Competitividad (España). GID de la Universidad de Burgos en Comunicación Audiovisual.

2 Universidad de Burgos, España. mdchicharro@ubu.es 
su versión cualitativa (ficciones preferidas, valoración de los personajes, de sus características narrativas, de su visualidad, de su calidad, de su capacidad de entretenimiento). Para este análisis, recurriremos a datos primarios, de carácter cuantitativo y cualitativo, obtenidos a través de nuestro propio trabajo de campo. El análisis y la interpretación de estos datos permitirán ofrecer un útil mapa de sus estrategias de consumo y de los discursos que en torno a ellas articulan.

\section{Palabras clave}

Ficción televisiva; jóvenes; consumo televisivo; España (Fuente: Tesauro de la Unesco). 


\section{Serial Fiction on TV: A Quantitative and Qualitative Approach to Consumption by Students of the Audiovisual Communication Program. The Spanish Case}

\section{Abstract}

This paper reflects on the relationship between young people and contemporary television fiction. More specifically, it analyzes the consumption trends among Audiovisual Communication students in Spain. We start from the supposed existence of a young subculture, where leisure practices are the variable of belonging. Audiovisual Communication students, in particular, oriented towards monitoring these products, are presented as a group whose use and consumption of teleseries are a sign of identity and distinction both in its quantitative dimension (times and products) and in its qualitative version (preferred fiction, evaluation of characters, their narrative features, their visuality, quality, ability to entertain). For this analysis, we will use primary, quantitative and qualitative data obtained from our own fieldwork. The analysis and interpretation of this data will allow us to offer a useful map of their consumption strategies and of the discourses surrounding them.

\section{Keywords}

Television fiction; young people; television consumption; Spain (Source: Unesco Thesaurus). 


\section{Seriados de ficção na televisão: aproximação quantitativa e qualitativa ao consumo dos estudantes de Comunicação Audiovisual. 0 caso espanhol}

\section{Resumo}

O presente trabalho reflete sobre a relação entre jovens e ficção televisiva contemporânea. Mais concretamente, analisa as tendências no consumo dos estudantes de Graduação em Comunicação Audiovisual na Espanha. Parte-se da suposição da existência de uma subcultura juvenil, onde as práticas de ócio fazem as vezes de variável de pertença. Os estudantes de Comunicação Audiovisual, especialmente orientados para o seguimento destes produtos, são apresentados como um grupo que faz de seus usos e consumos de séries de televisão um sinal de identidade e distinção tanto em sua dimensão quantitativa (tempos e produtos) quanto em sua versão qualitativa (ficções preferidas, avaliação dos personagens, de suas características narrativas, de sua visualidade, de sua qualidade, de sua capacidade de entretenimento). Para esta análise, recorreremos a dados primários, de caráter quantitativo e qualitativo, obtidos através de nosso próprio trabalho de campo. A análise e a interpretação destes dados permitirá oferecer um mapa útil de suas estratégias de consumo e dos discursos que em torno a estas articulam.

\section{Palavras-chave}

Ficção televisiva, jovens, consumo televisivo, Espanha (Fonte: Tesauro da Unesco). 


\section{Introducción}

Tradicionalmente, el periodo juvenil ha sido considerado la etapa de formación en la que adquirir las competencias y los aprendizajes necesarios para integrarse en el medio adulto, en la cual se obtiene ya autonomía residencial y económica. Coincide con un rango de edad que los estudios de juventud han ido prolongando sucesivamente, dadas las dificultades para alcanzar y consolidar estos logros. De este modo, el itinerario hacia el medio adulto es cada vez menos lineal y, en cambio, con frecuencia, aparece cargado de avances y de retrocesos que colocan muy a menudo a los sujetos en situaciones ambiguas, ya no estrictamente juveniles, todavía no adultas.

Además de la formación y el aprendizaje, el ocio y el tiempo libre es otra de las dimensiones que definen de manera central el espacio juvenil. La disponibilidad, así como los usos concedidos al tiempo vacío de obligaciones (Callejo, 1995) son una de sus marcas distintivas. Ajeno a las responsabilidades de la madurez, el joven se organiza en torno a actividades lúdicas, a veces, en soledad, pero, sobre todo, en compañía de su referente de sociabilidad: el grupo de pares. Alrededor de estos se articulan espacios de entretenimiento y diversión, que, además, tienen sentidos socializadores y educativos, ricos en aprendizajes cognitivos, sociales y emocionales (Chicharro, 2011a). Además, dan forma a actividades a través de las que mostrar la conexión con el propio grupo y su distinción en relación con otros.

Aunque ser joven es algo más que una cuestión subcultural e identitaria, esta fase está asociada a un conjunto de valores, normas y símbolos, dentro de los que se incluyen elementos materiales (ropa, estética, recursos económicos), incluso comportamentales (conductas y actitudes). Elementos culturales, por otro lado, que sus miembros sustentan y defienden como patrimonio que los distingue y que marca diferencias en relación con sus mayores. De ahí que ser joven signifique no ya aprender a ser adulto, sino también socializarse en lo juvenil o adquirir los conocimientos necesarios para ejercer plenamente ese papel. Las prácticas de ocio y tiempo libre, y entre ellas los consumos audiovisuales y digitales, se convierten en elementos que conforman la idiosincrasia de este grupo de edad. 
El sentido expresivo y hedonista prima en el consumo juvenil de ficción televisiva. Así, son en especial reconocidos los personajes que provocan risa y humor. Sin embargo, sus utilidades sobrepasan el plano meramente lúdico. Sus personajes y tramas permiten establecer mecanismos de identificación, reafirmación y apropiación entre mensaje y consumidor, reforzando aprendizajes axiológicos, emocionales, actitudinales y cognitivos (Aierbe, Orozco y Medrano, 2014; Rubio y San Martín, 2012). En el plano más afectivo, los jóvenes consumidores reconocen la importancia de identificarse con sus personajes, proyectando sobre ellos deseos, objetivos, ideales. Señalan también el valor de establecer conexiones y continuidades entre realidad, ficción y juego, a través de historias y personajes realistas (Bermejo, 2012). De este modo, los relatos audiovisuales pueden ayudar, por ejemplo, a configurar imaginarios sobre la corporalidad y la actitud en función del género, fomentando, habitualmente, las posiciones más conservadoras (Muros, Aragón y Bustos, 2013; Chicharro, 2013). En este sentido, también las nuevas formulaciones televisivas, a pesar de su aparente modernidad, reproducen y conservan las diferencias de género, frente a las que la coeducación y la alfabetización educativa pueden ser vías igualadoras (Belmonte y Guillamón, 2008).

\section{Material y métodos}

El presente trabajo pretende explorar algunas de las dimensiones que dan forma al consumo de ficción televisiva de los jóvenes universitarios, estudiantes de Comunicación Audiovisual, en el caso español. Pretendemos conocer algunas de las dimensiones más objetivas de su consumo (tiempo de consumo, soportes utilizados o tipos de ficciones favoritas, entre otros), así como aspectos más subjetivos y difíciles de registrar, como su percepción de las ficciones respecto de los personajes, la narrativa y el guion, la visualidad, la capacidad de conexión con los públicos, la calidad televisiva o la capacidad de entretenimiento.

Partimos del supuesto general de que los jóvenes estudiantes de Comunicación, situados en etapa de tránsito, formación y aprendizaje, tienden a construir señas de identidad subculturales, entre las que cobran especial importancia prácticas de ocio, como el consumo de ficción (Falcó y Díaz, 
2014). Este se caracteriza, entendemos, por su carácter amplio, variado y heterogéneo, si bien algunos formatos harán las veces de "teleseries imprescindibles" en torno a los que manifestar la pertenencia al grupo.

La elección de nuestro universo de estudio se justifica desde varias perspectivas. Responde a criterios de accesibilidad, que han hecho posible la aplicación de una costosa estrategia metodológica triangulada, recurriendo a un subgrupo juvenil con el que mantenemos especial cercanía. Pero la elección de este grupo implica ciertas ventajas respecto de la validez metodológica. Por un lado, contiene algunas de las situaciones típicamente juveniles: el estudio y la formación forman parte de su estilo de vida. Por otro, algunas de sus particularidades hacen de este un subgrupo distintivo respecto del consumo audiovisual: se muestra en especial orientado a los mensajes audiovisuales, de ahí su consumo intensivo y veloz, que es experimentado como parte de su formación profesional, y cuenta con competencias y cualificaciones audiovisuales específicas. Su paso por el sistema educativo formal alimenta una relación más consciente y crítica con la cultura audiovisual. Tanto los contenidos impartidos en el aula como la propia conversación interpares refuerza un interés reflexivo sobre los productos televisivos.

Sobre estas premisas, nuestras fuentes y material de análisis han sido los siguientes:

1) Datos primarios cuantitativos, obtenidos a través del método de encuesta. ${ }^{3}$ El cuestionario, integrado por 30 preguntas, fue administrado directamente a una muestra de 180 estudiantes del Grado en Comunicación Audiovisual de la Universidad Complutense de Madrid. Situados en una horquilla de edad entre los 18 y los 25 años, con una distribución de sexos de 76 varones y 104 mujeres, la muestra, algo cargada en la región madrile-

3 La realización de la encuesta fue posible gracias a la comprometida ayuda de Ángela García Gómez y Nerea Punzano Díaz, alumnas colaboradoras en el proyecto FEM2011-27381, que efectuaron la codificación y tabulación de los datos. Nuestros agradecimientos, además, a los alumnos de Comunicación Audiovisual del Centro de Estudios Superiores Felipe II, de la Universidad Complutense de Madrid y de la Universidad de Burgos, que colaboraron con tan buena disposición en el proceso de encuesta y en las entrevistas en profundidad. El apoyo del profesor Salvador Gómez de la Universidad de Valladolid fue indispensable para la depuración y administración del cuestionario. 
ña, es ciertamente diversa desde una perspectiva geográfica. El trabajo de campo fue realizado en junio de 2013.

Estos primeros datos cuantitativos fueron contrastados con una segunda batería de informaciones obtenida en otoño de 2013, en junio de 2014 y diciembre de 2015, en la que se pulsaron, con preguntas abiertas, las tendencias de consumo entre un segundo colectivo de estudiantes de Comunicación Audiovisual (49, 48 y 51 estudiantes, respectivamente, de la Universidad de Burgos), que ejercieron las veces de grupos de control. Estos validaron las preferencias de consumo expresadas en el material de la encuesta, e incidieron en la dispersión de sus prácticas. Se mencionaron en el entorno de 96 formatos para definir sus consumos habituales.

2) Datos primarios de corte cualitativo, obtenidos a través de la técnica de la entrevista en profundidad, y que han matizado, ampliado y explicado buena parte de los datos cuantitativos. A lo largo del otoño de 2013 y diciembre de 2015, fueron realizadas 20 entrevistas en profundidad a estudiantes de la universidad madrileña y burgalesa. La elección de los sujetos obedecía a un muestreo de corte intencional, de acuerdo con variables, como el género y el nivel de conocimiento y de consumo de ficción televisiva.

Esta apuesta triangulada, en la que se combinan técnicas de investigación cuantitativas y cualitativas, es el resultado de un diseño de investigación flexible, caracterizado por un gran margen de apertura, que se enlaza con esquemas de investigación emergentes, más propios de la lógica cualitativa, definidos por perspectivas metodológicas, como la grounded theory (Strauss y Corbin, 1990; Strauss, 1987; Vallés, 1997).

\section{Análisis y resultados}

Elgrueso de nuestra muestra dice situar su consumo por debajo de la media de la población española. A lo largo de 2012, el consumo medio de televisión en España fue de 244 minutos, por encima de las 4 horas (Barlovento Comunicación, 2013). Entretanto, la mayoría de nuestros entrevistados sitúa su tiempo habitual por debajo de las 2 horas diarias, mientras que $33.3 \%$ de la muestra señala que su visionado de televisión se sitúa entre las 2 y las 5 
horas diarias. En este sentido, las entrevistas en profundidad sugieren categorías, como la falta de interactividad del medio, la pasividad que imprime a la figura del espectador o la falta de control del receptor sobre el mensaje y su administración, como algunas posibles explicaciones a este consumo relativamente controlado de televisión (tabla 1).

Tabla 1. Consumo diario de televisión

\begin{tabular}{|c|c|c|}
\hline & Porcentaje válido & Porcentaje acumulado \\
\hline Nada & 8.4 & 8.4 \\
\hline Menos de 1 hora & 21.3 & 29.8 \\
\hline Menos de 2 horas & 32.6 & 62.4 \\
\hline Entre 2 y 5 horas & 33.7 & 96.1 \\
\hline Más de 5 horas & 3.9 & 100 \\
\hline
\end{tabular}

Datos primarios.

Ahora bien, los datos sobre consumo televisivo cuantitativo de estos grupos exigen, no obstante, algunas matizaciones que tienen que ver con la manera particular que este colectivo tiene de apropiarse de tales productos. En este sentido, es sobre todo ilustrativo señalar la relación casi indisoluble entre televisión, ordenador, incluso, red de redes. Las cohortes juveniles se distinguen por los productos de ficción particulares que gustan y disfrutan, pero, además, por los medios y los soportes para su consumo.

El uso de la red, vía incipiente de visionado de televisión, es ya extensivo entre el grupo de edad entre 15 y 24 años (Asociación para la Investigación de los Medios de Comunicación [AIMC], 2015), si bien con grandes diferencias en función del sexo, ya que los varones son en especial internautas. Por edades, los datos del Estudio General de Medios para marzo de 2014 señalan como dentro de los que dicen haber utilizado internet muy recientemente ("usuarios ayer") que $18.3 \%$ tenía entre 14 y 24 años, frente a $24.9 \%$ de usuarios entre 35 y 44 años (AIMC, 2014). No obstante, internet se revela como el medio favorito para el grueso de los y las jóvenes españoles (López, Medina y Gónzalez, 2013).

Del mismo modo, estos trabajos cuantitativos señalan que su uso es eminentemente recreativo y con mucha menos frecuencia se emplea para 
tareas escolares (Organización para la Cooperación y el Desarrollo Económicos [OCDE], 2010). De hecho, la actividad de "usar el ordenador" es la que, dentro de las prácticas de ocio y tiempo libre, experimenta un mayor crecimiento desde una perspectiva evolutiva: desde $61.6 \%$ en 2004 hasta $93.1 \%$ en 2012 (Instituto de la Juventud [Injuve], 2005, 2011).

El uso de internet como soporte a través del que consumir televisión es ya un hecho constatado y cuantificado en el caso español. Ya en 2011, $18 \%$ de los internautas accedía el mismo día a la televisión tradicional y a través de internet, cifra que se eleva a $54 \%$ si incluimos los 30 últimos días. El $11 \%$ del consumo de televisión entre los internautas se realiza en línea, siendo el dispositivo más utilizado el ordenador portátil. El visionado en directo (streaming) es, por otro lado, la fórmula hegemónica (AIMC, 2012).

En los y las jóvenes universitarios estudiados, el ordenador es, sin ningún género de duda, el soporte favorito para su consumo, en las variadas formas que permite (visionado en línea, descarga y posterior consumo). Aún a costa de las tan frecuentes descargas ilegales, este soporte les permite manejar los tiempos, decidiendo los momentos del visionado, pero también permitiendo personalizar paradas y cortes (tabla 2).

Tabla 2. Vías de consumo televisivo

\begin{tabular}{|c|c|c|}
\hline & Porcentaje válido & Porcentaje acumulado \\
\hline Televisión & 24.9 & 24.9 \\
\hline Ordenador & 68.9 & 93.8 \\
\hline DVD & 6.2 & 100.0 \\
\hline
\end{tabular}

Datos primarios.

La ficción televisiva ha ampliado sus circuitos de distribución y visionado, apoyándose en la red de redes para llegar, sobre todo, a los públicos juveniles. De ahí que el conjunto de las cadenas se apoyen en páginas web adyacentes, a través de las que los espectadores pueden acceder a fotos, foros, blogs, fichas de los personajes, making of, incluso, a conversaciones en tiempo real con actores y guionistas, articulando vías de interactividad entre mensaje y espectador. Los preestrenos en red o la posibilidad de visionar 
teleseries desde las páginas web de las respectivas cadenas son otros de los usos televisivos de la red de redes que también hace las veces de escaparate de merchandising.

Además, esta vía permite que el usuario produzca sus propios contenidos, personalizándolos y escapando a los controles de la rentabilidad y la audimetría. Los medios pierden así control en favor del consumidor que, a su vez, es productor (Galán y Del Pino, 2010). Las webseries españolas, como Cálico Electrónico, la primera dentro de esta fórmula (2004), o Malviviendo (2008), se organizan en forma de pequeñas entregas que adecúan sus tiempos a los imperativos de plataformas, como YouTube. Algunas, como Quévida más triste (La Sexta) o Chessboxing (Antena 3), se han convertido también en productos emitidos por la pequeña pantalla y han seguido circulando por la red (Redondo, 2013). La comunicación informal y el marketing viral son algunas de sus vías de promoción.

El uso de la red añade otras ventajas para nuestro colectivo. Permite escapar a las censuras adultas y plantear lecturas negociadas, subculturales, incluso, contraculturales. Permite registros más espontáneos, más libres y menos regulados, en los que se señalan conflictos más cercanos y menos visibles en un medio tan familiar como la televisión. Los videoblogs, plataformas como YouTube, redes sociales como Facebook o Twitter y servicios de telefonía móvil como WhatsApp son otros instrumentos que permiten materializar estos usos, convirtiendo algunos formatos en visionado obligado para sus iguales.

En este sentido, los espectadores e internautas juveniles conectan muy claramente con algunos perfiles contemporáneos, en los que televisión y red adquieren un sentido complementario. Así, el "espectador fan", busca información adicional a través de la red; el "espectador consumidor" encuentra en la red merchandising de productos televisivos; el "espectador cibernauta" añade contenidos al portal televisivo (Siapera, 2004). Además, productos y pautas de consumo transmedia vinculan la televisión con el cómic, el libro o con los videojuegos. En este escenario, la fandom cultura se hace más accesible y se incrementa la capacidad del espectador de actuar sobre el relato (Mittell, 2010; Dinehart, 2008). 
Otra de las características del consumo de ficción de los entrevistados hace referencia a su tendencia a simultanearlo con otras actividades. Aunque el elenco de tareas que dicen simultanear con su visionado de ficción es ciertamente limitado, el hábito de realizar varias tareas a la vez (multitask) pone de manifiesto el desarrollo, sobre todo, a través del uso de nuevas tecnologías, de características cognitivas, como la capacidad para procesar información de manera rápida, o de diversificar la atención, organizando datos simultáneamente, si bien de manera menos intensa y menos centrada en un único aspecto (Gros, 2004; Prensky, 2001; Salomon, 2000). En este sentido, chatear y navegar son las actividades que los entrevistados dicen simultanear con más frecuencia con el visionado de teleseries. Caben, no obstante, otras tareas, tales como la lectura, el dibujo, incluso, los trabajos de clase. Tan solo $11.2 \%$ de los encuestados dice centrar toda su atención en la ficción, no haciendo "nada más" cuando la desarrolla.

Ya en el plano de sus preferencias de consumo, los jóvenes encuestados muestran, sin lugar a dudas, un mayor interés por la ficción de producción extranjera. El discurso de las entrevistas en profundidad señala cómo sitúan esta respecto de la calidad superior, en términos narrativos, técnicos y estéticos, de dirección de actores, de seguimiento de público y, por supuesto, de presupuesto: "El resultado final es muy difícil de lograr. Son mucho más visuales” (Lorena). Es más, en ocasiones, ese sello de calidad se asocia exclusivamente con este tipo de producciones: "El problema es que dices, está bien para ser española” (Alex) (tabla 3).

Tabla 3. Consumo de ficción nacional y extranjera

\begin{tabular}{|c|c|}
\hline Tipo de ficción & Porcentaje válido \\
\hline Extranjera & 68.9 \\
\hline Nacional & 7.9 \\
\hline Ambas por igual & 23.2 \\
\hline
\end{tabular}

Datos primarios.

Tanto para la ficción extranjera, como para la española, la comedia de situación, en sus diferentes formulaciones, es el género preferido de los entrevistados. Los géneros más lúdicos y hedonistas son los que lideran los 
rankings tal y como señala la tabla 4. Las preferencias extraídas del grupo de control entrevistado en 2014 y 2015 también redundan en la popularidad de formatos, como Los Simpson, Modern family, How I met your mother o Big band theory.

Los Simpson (Fox, 1989) se presenta claramente como la más popular de las producciones:

Quién no ha visto Los Simpson... Son dibujos animados, pero nunca estás viendo dibujos (Pablo).

A las dos no pienso en ver otra cosa (Lorena).

A lo largo de sus ya veinticinco temporadas, este relato de animación para todos los públicos ha hecho de su crítica hacia la sociedad americana, los diálogos chispeantes o el carácter transgresor de sus personajes algunas de las señas distintivas del formato. En este sentido, su carácter hilarante, así como su humor ácido, son las cualidades más destacadas por los seguidores del formato. Su sencillez, su capacidad para fomentar la evasión del espectador o su carácter familiar son otros de los valores destacados.

No obstante, algunas otras cuestiones más prácticas y logísticas parecen fomentar su visionado. El horario de emisión, su accesibilidad en diferentes canales, la duración de los capítulos, su carácter autoconclusivo, que no obliga a un seguimiento constante del formato, son otros de los aspectos valorados por tan pragmáticos espectadores:

La hora de comer... es idónea, es tradición... El niño o el joven a esa hora, es él el que toma la decisión (Pablo).

A la hora de comer [...] Los Simpson más por costumbre o ritual que por auténtica devoción por la serie (Diego).

Dura poco... en plan, una hora dos capítulos (Lorena).

Son autoconclusivos, no hace falta estar pendiente de la continuación... se pueden ver con los padres (Víctor).

Me habré convertido en seguidor simplemente porque dondequiera que vaya en algún canal estarán dándolos (Christian). 
Los entrevistados manifiestan un profundo conocimiento del formato, a través de indicadores, como la repetición del visionado o la distinción entre las diferentes temporadas:

Da igual que te sepas el capítulo, se sigue poniendo (Elisabet).

Me gustan más los repetidos (Alejandro).

A partir de la temporada quince pierden mucho (David).

Las primeras diez temporadas te marcaban (Christian).

\section{Tabla 4. Consumo frecuente o habitual de ficción de producción extranjera}

\begin{tabular}{|c|c|c|c|c|}
\hline & & Bastante (A) & Habitualmente (B) & $A+B$ \\
\hline 1 & Los Simpson & 25 & 66.1 & 91.1 \\
\hline 2 & Family guy & 32.8 & 28,9 & 61.7 \\
\hline 3 & Big Bang theory & 21.1 & 34.4 & 55.5 \\
\hline 4 & How I met your mother & 23.9 & 30.6 & 54.5 \\
\hline 5 & House & 27.8 & 18.3 & 46.1 \\
\hline 6 & CSI Miami & 17.2 & 26.1 & 43.3 \\
\hline 7 & The mentalist & 24.4 & 15 & 39.4 \\
\hline 8 & Friends & 21.1 & 16.7 & 37.8 \\
\hline 9 & Modern family & 10 & 26.7 & 36.7 \\
\hline 10 & The walking dead & 10 & 25.6 & 35.6 \\
\hline 11 & Lost & 26.1 & 9.4 & 35.5 \\
\hline 12 & Sex and the city & 11.1 & 23.9 & 35 \\
\hline 13 & Grey's anatomy & 15.6 & 16.1 & 31.7 \\
\hline 14 & Desperate housewives & 14.4 & 16.7 & 31.1 \\
\hline 15 & Two and a half man & 14.4 & 13.9 & 28.3 \\
\hline 16 & Gossip girl & 10 & 17.8 & 27.8 \\
\hline 17 & Breaking bad & 3.3 & 22.2 & 25.5 \\
\hline 18 & Heroes & 11.7 & 12.2 & 23.9 \\
\hline 19 & Bones & 14.4 & 7.8 & 22.2 \\
\hline 20 & Criminal minds & 12.8 & 8.9 & 21.7 \\
\hline 21 & Madmen & 10 & 12.8 & 22.8 \\
\hline 22 & Dexter & 8.9 & 18.9 & 17.8 \\
\hline 23 & Game of thrones & 7.8 & 8.3 & 16.1 \\
\hline 24 & Misfits & 7.2 & 7.2 & 14.4 \\
\hline 25 & Prison break & 16.2 & 4.5 & 10.7 \\
\hline
\end{tabular}

Datos primarios. 
Family guy (Fox, 1999) es valorado por los entrevistados, necesariamente, en relación con el referente de las series de animación: Los Simpson. De ahí que sea percibido como un relato más abrupto, exagerado, osado, combativo y crítico. No obstante, suscita pasiones y odios más intensos. Para algunos es una copia imperfecta ("Han imitado a Los Simpson, pero no lo han conseguido", Elisabet), para otros es un producto estrella ("Me gusta mucho", Alejandro).

Big Band theory (CBS, 2007) a modo de comedia de situación, protagonizada por científicos, brillantes en su trabajo, si bien con claras carencias de inteligencia social, que ejemplifican el valor de la cultura audiovisual y digital popular, encarnando el estereotipo de joven friki, hasta la fecha ausente de los relatos de ficción televisiva. De este modo, la teleserie no solo está llena de referencias a principios y teorías físicas, sino también a series, películas de ciencia ficción y aventuras de culto, videojuegos, cómics, juegos de rol, conceptos informáticos y cibernáuticos.

De ahí que los jóvenes espectadores parezcan valorar, sobre todo, la peculiaridad y originalidad de sus personajes o el ingenio de los guiones. En este sentido, la identificación que se activa parece ser una de las claves explicativas de su consumo.

Yo soy bastante friki, y entiendo la mayor parte de la serie, las cosas que dicen, las frases que tienen, las situaciones. Por eso los personajes me hacen mucha más gracia... habla de una cultura muy juvenil (Alejandro).

Son para gente friki. Si eres friki lo entiendes (David).

Me volví seguidor por su capacidad para captar casi todas las perspectivas del mundo freak (Christian).

How I met your mother (CBS, 2005) o Modern family (ABC, 2009) son otras de las comedias bien puntuadas en el ranking de consumo de nuestros entrevistados, si bien despiertan menos interés y se distinguen menos en términos cualitativos. Mención especial merece Friends (NBC, 19942004), formato que, a pesar de su "antigüedad" relativa, sigue contando 
con el parabién de esta audiencia. En este sentido, las reposiciones emitidas desde canales españoles, como Cuatro y Factoría de Ficción, han alimentado la popularidad y el consumo sostenido de un formato valorado por sus personajes jóvenes y diferenciados, que representan problemas de esta edad y que ejemplifican el modelo americano en su versión más edulcorada y relacional.

Los datos sobre "no consumo" se muestran igualmente consistentes con los ya enunciados. Los formatos con forma de comedia son aquellos que en menor medida "nunca se han visto". Es llamativo cómo 10 de los 25 formatos analizados son desconocidos para al menos $50 \%$ de los encuestados. Los datos confirman, por tanto, la hipótesis de que el consumo juvenil de ficción tiene un carácter disperso, y que son muy pocas las producciones en torno a las que se concentra el grueso de este público y que hacen las veces de "series indispensables".

Los datos de encuesta ponían igualmente de manifiesto su interés por consumir algunas ficciones concretas: en especial Game of thrones y Breaking bad. No en vano, ambas teleseries encabezan el listado de espacios más descargados ilegalmente en la red (Scarperllini, 2013) o más comprados vía internet (El Periódico, 2015). Del mismo modo, los grupos de control entrevistados en 2013, 2014 y 2015 sitúan en la cabeza de sus preferencias ambas ficciones.

Game of thrones (HBO, 2011) remite al espectador a las marcas propias del género de aventuras: fantasía y espada y brujería. De una gran densidad narrativa, inesperada en sus conflictos y en sus resoluciones y con cierta dosis de sexo y violencia parece, no obstante, haber conectado plenamente con las preferencias e intereses del colectivo estudiado. La diversidad y el atractivo de sus historias, pobladas de personajes sorprendentes que favorecen la atención, así como la visualidad, que los jóvenes espectadores entienden como seña de calidad, parecen ser algunas de las claves de su masiva aceptación.

Pensaba que no me iba a gustar... pero sí... mucho... (Los personajes) resultan sorprendentes... están muy bien... Y si ves cómo está hecho... (Lorena). 


\section{Tabla 5. Porcentaje de sujetos que nunca ha consumido algunas ficciones extranjeras}

\begin{tabular}{|c|l|c|}
\hline 1 & Los Simpson & 0.6 \\
\hline 2 & Family guy & 7.8 \\
\hline 3 & How I met your mother & 17.8 \\
\hline 4 & House & 18.3 \\
\hline 5 & Big Bang theory & 21.1 \\
\hline 6 & Lost & 27.8 \\
\hline 7 & The mentalist & 32.2 \\
\hline 8 & CSI Miami & 33.3 \\
\hline 9 & Modern family & 37.8 \\
\hline 10 & Grey's anatomy & 39.4 \\
\hline 11 & Friends & 41.1 \\
\hline 12 & Bones & 41.7 \\
\hline 13 & The walking dead & 42.2 \\
\hline 14 & Desperate housewives & 44.4 \\
\hline 15 & Two and a half man & 50 \\
\hline 16 & Gossip girl & 50 \\
\hline 17 & Dexter & 51.7 \\
\hline 18 & Sex and the city & 51.7 \\
\hline 19 & Prison break & 53.6 \\
\hline 20 & Breaking bad & 57.2 \\
\hline 21 & Criminal minds & 57.2 \\
\hline 22 & Heroes & 61.1 \\
\hline 23 & Game of thrones & 62.8 \\
\hline 24 & Mad men & 65.6 \\
\hline 25 & Misfits & 77.8 \\
\hline & & \\
\hline
\end{tabular}

Datos primarios.

Me siento identificada con varios (personajes). Al haber tantas tramas... El tono visual de la serie me parece increíble, tan cinematográfica, tan película... Cada capítulo es una superproducción... (Elisabet).

Los personajes están muy bien hechos... Es muy fácil tenerle cariño a unos personajes y odiar a otros... Con la producción que tiene... (Alejandro).

Los personajes, hay algunos que están muy bien hechos. Es casi como me la había imaginado. Muy bonita (Mariela). 
Leí por foros que era algo que realmente sorprendía a quien lo viese y a mí siempre me ha gustado... las historias que cambien cuando menos me lo espero, y empecé a verla, aunque a mí la temática Edad Media nunca me ha llamado la atención (Christian).

Todos pueden sufrir una traición, morir en la guerra que tiene lugar de la trama y, en definitiva, padecer la condición humana independientemente de la popularidad o peso del personaje de la trama (Diego).

Breaking bad (AMC, 2008-2013) es otra de las consideradas "ficciones estrella” por parte de buena parte de nuestros entrevistados. Considerada una de las mejores ficciones dramáticas de todos los tiempos, su protagonista, a través del oportuno arco de transformación, suscita en el espectador dudas morales en torno a la legitimidad de un personaje con el que el espectador llega a empatizar. Esta lógica parece ser una de las principales conexiones de nuestros jóvenes espectadores con el relato. La capacidad de la ficción para mantener la atención y crear intriga es uno de los aspectos más valorados, entendido como sello de calidad.

Me parece excelente. Desde el guion, perfectamente escrito, redondo y con todos los cabos atados una vez terminada la serie, hasta la realización de cada capítulo; está genialmente dirigida, tremendamente bien interpretada, con una posproducción de sonido bestial... Visualmente es increíble. Es puro cine. Creo que no le falta ni sobra nada (Pelayo).

De las mejores... Los guiones me parecen muy buenos. Y el protagonista es lo más... No hay capítulo malo. Te engancha aunque no te guste el tema (Alejandro).

Perfecta, cada temporada va a más... eso gusta mucho. [...] Tienes que estar todo el rato viéndola, exige un visionado muy activo (David).

Me gusta ver la evolución. Está bien llevada.... parece realista (Mariela).

Yo creo que te engancha para ver cómo evoluciona. El personaje protagonista me gustaba mucho (Lorena).

En el plano de la ficción doméstica española, la comedia sigue siendo el género favorito. Encabezando la galería de preferencias se sitúa la producción Aquí no hay quien viva (Antena 3, 2003-2006), que ha llegado a alcanzar cuotas de pantalla de $40 \%$. En clave de humor surrealista narra 
los particulares avatares y pequeños conflictos cotidianos de un grupo de hogares que dan forma a la comunidad de vecinos de Desengaño 21. Poblada por personajes claramente estereotipados y previsibles, no obstante, consiguen hacer de este un formato de humor blanco muy apropiado para el prime time de los domingos. Posteriormente, la producción "clónica”, de los mismos creadores, La que se avecina (Telecinco, 2007), extrapolará las tramas vecinales a la urbanización el Mirador de Montepinar. En ambos casos, la familiaridad de las tramas, el ingenio de los guiones, su coralidad, así como el carácter rígido y plano de la galería de personajes, parecen ser algunas de las claves de éxito. Al mismo tiempo, su reposición posterior en Neox y Paramount Comedy o Factoría de Ficción, así como su programación en horarios de mediodía, ha facilitado la popularización y el visionado de ambos formatos.

A pesar de la obvia cercanía entre ambas producciones, como indica la demanda interpuesta por Antena 3 a su rival Telecinco por vulnerar sus derechos de propiedad intelectual, los seguidores de la primera exacerban las diferencias y destacan su carácter genuino y original.

Soy fan de Aquí no hay quién viva (Pablo).

La que se avecina, es muy repetitiva, hay muchas diferencias (con Aquí no hay quien viva) (Alejandro).

Frente a Aquí no hay quién viva, ya han cambiado los personajes (Mariela).

En cualquiera de los casos, sus seguidores destacan el interés de sus personajes, la fuerza y el ingenio de los diálogos, la rapidez en la que se suceden las situaciones ("No paran de pasar cosas", David), la capacidad comunicativa de los personajes (“Sin que digan nada, lo estás viendo”, David).

Entretanto, la comedia Aida (Telecinco, 2005-14) es descrita como un producto más complejo, con personajes originales y atractivos, si bien el grueso de los entrevistados dice acusar el carácter repetitivo de un producto que ya enganchó a algunos de ellos en su precuela, 7 vidas (Telecinco, 1999-2006). Su estratégica situación en la parrilla televisiva, los domingos, 
en torno a la "hora de la cena", así como su humor sorprendente y surrealista, parecen ser determinantes para su seguimiento (tabla 7).

Tabla 7. Consumo de ficción nacional

\begin{tabular}{|c|l|c|c|c|}
\hline & & Bastante (A) & Habitualmente (B) & A + B \\
\hline 1 & Aquí no hay quién viva & 35.6 & 28.9 & 64.5 \\
\hline 2 & Aída & 37.8 & 21.1 & 58.9 \\
\hline 3 & Los Serrano & 28,3 & 23.9 & 52.2 \\
\hline 4 & La que se avecina & 22.2 & 25 & 47.2 \\
\hline 5 & Los hombres de Paco & 21.7 & 17.8 & 39.5 \\
\hline 6 & Física o química & 18.9 & 13.9 & 32.8 \\
\hline 7 & El internado & 16.1 & 16.1 & 32.2 \\
\hline 8 & Cuéntame & 16.1 & 10 & 26.1 \\
\hline 9 & Hospital central & 15.6 & 10 & 25.6 \\
\hline 10 & Los protegidos & 14.4 & 11.1 & 25.5 \\
\hline 11 & Qué vida más triste & 13.9 & 3.9 & 17.8 \\
\hline 12 & Águila Roja & 6.7 & 7.8 & 14.5 \\
\hline 13 & El barco & 3.3 & 8.3 & 1.6 \\
\hline 14 & Amar en tiempos revueltos & 6.1 & 4.4 & 10.5 \\
\hline
\end{tabular}

Mención especial merece el género de la dramedia, ejemplificada en la ya clásica teleserie Los Serrano. Producida por Globomedia y emitida por Telecinco entre 2003 y 2008, las reposiciones desde Factoría de Ficción han prolongado la vida de un formato presente en el imaginario de jóvenes y adultos españoles. Las tramas se organizan en torno a las vicisitudes familiares de los Serrano, familia reconstituida a partir del matrimonio en segundas nupcias de Diego (Antonio Resines) y Lucía (Belén Rueda), que aportan sus respectivos hijos. Los pequeños avatares y conflictos familiares dinamizan la acción, mostrando al espectador una familia ideal y exitosa, poblada de personajes sencillos y familiares, en la que los problemas se resuelven siempre de la manera socialmente deseable. Para la mayoría de los entrevistados, el consumo de Los Serrano se inscribe en el espacio familiar. Se trata de un producto que perciben como historia idealizada: "Todo muy bonito, muy a la española ... no te sorprendes pero le tomas cariño a los personajes" (Alejandro). "Muy familiar” (Pablo). 
Esa condición de producto familiar se extiende a Cuéntame, emitido por TVE 1, desde 2001 ("Lo veía siempre en familia”, Elisabet). Si bien no forma parte de los formatos específicamente juveniles, es bien popular entre el conjunto de los públicos. Esta ficción histórica recurre de nuevo a la unidad narrativa de la familia para retrotraer al espectador al pasado más reciente de la sociedad española. Situada en origen en la etapa del tardofranquismo, el relato irá señalando el proceso de apertura creciente e incluso de transición y consolidación democrática en el que se inscribe la sociedad española. Las aventuras y desventuras, los logros y las tristezas de la familia Alcántara serán el hilo conductor para mostrar cómo una familia cambia como la propia sociedad en la que se sitúa.

De hecho solo 28.3 de nuestros encuestados nunca ha visto Cuénta$m e, y$ aunque sus cifras de seguimiento habitual y frecuente son limitadas, se trata de productos de cierto reconocimiento o con "valor de marca" (Medina, 2007). En ambos casos, su consumo se sitúa en tiempos pretéritos y adolescentes, en los que "ver la tele" era una actividad familiar, influida por sus diversos grupos de pertenencia, familiar y de pares ("En el colegio, el que no la veía...", Alejandro).

\section{Conclusiones}

El seguimiento de ficción televisiva que realizan los estudiantes de Comunicación Audiovisual es diverso, abierto y heterogéneo. De ahí la dificultad para apuntar preferencias y consumos e identificarlos con los valores y las prácticas dominantes en este colectivo. Del mismo modo, su uso es muy pragmático, calculado, intencional y documentado. Frente a otros grupos de edad, son conscientes de la variedad y la magnitud de la oferta ("Hay tantas cosas", Alejandro), por lo que manejan información a priori, escogiendo los formatos que pueden ser de su interés y consumiéndolos, sobre todo, a través de la red. Se trata, básicamente, de un visionado intensivo, centrado en los momentos de tiempo vacío ("Me cuesta mucho ver un capítulo y esperar a la semana siguiente”, David).

No obstante, algunas pautas de consumo hacen las veces de puntos fijos que, en buena medida, dan forma a la identidad de un grupo que se 
distingue por su conocimiento audiovisual. El gusto por la ficción extranjera y por la comedia de situación es hegemónico. El interés por productos, como Game of thrones y Breaking bad, hacen de estas "teleseries casi imprescindibles" para pertenecer $y$ afirmarse en el grupo.

Estos jóvenes escogen los formatos a través de cauces eminentemente informales: los consejos de amigos y conocidos, la temática y características generales o las críticas volcadas en la red, ya sean de expertos, ya sean de seguidores. Otras cuestiones más vinculadas con la logística del formato, como la duración de los capítulos y las temporadas, son importantes criterios de elección. Del mismo modo, la organización del producto en forma de temporadas completas, que permitan su consumo total, sin correr el riesgo de que la productora interrumpa el formato, es otro de los elementos a tener en cuenta ("Para mí es importante saber que la temporada está cerrada”, David). Finalmente, los más socializados y entrenados recurren a criterios algo más especializados, como es la cadena para la que el formato ha sido realizado ("Si es de la HBO", David).

Una vez iniciados en un producto, el entretenimiento y el mantenimiento de expectativas parecen condiciones indispensables para continuar con un visionado que tiene un sentido eminentemente hedonista. "Que no me aburra ... si me resulta muy repetitiva, dejo de verla" (Lorena). La acción ("Acción... muy intensa", Víctor) y las tramas románticas, en las jóvenes féminas siguen siendo elementos que fomentan y mantienen el visionado. La evasión, mediada además por sus conocimientos narrativos y técnicos sobre televisión, guía su visionado: "Espero que me entretenga y tampoco le exijo que me haga pensar. Lo concibo como puro entretenimiento. Buen guion, buenos personajes, que estén bien hechas, buena documentación ... por lo que son mis conocimientos" (Pablo).

En este sentido, este trabajo pone de manifiesto cómo el estudio del consumo cultural juvenil exige un seguimiento constante, dada la rapidez con la que actividades, prácticas y productos son apropiados, pero también desechados y sustituidos. Resta todavía profundizar en los elementos que conectan psicológicamente a los jóvenes con sus ficciones favoritas. El 
consumo audiovisual es una de las señas de identidad de ciertos colectivos juveniles y su conocimiento nos acerca a las cosmovisiones y los universos culturales de nuestros jóvenes y, por extensión, a sus prácticas y rutinas más materiales. De ahí la necesidad de profundizar en los gustos y las mentalidades de las cohortes de jóvenes, tarea en la que se ha centrado este texto.

\section{Referencias}

Aierbe, A., Orozco, G. y Medrano, C. (2014). Family context, television and perceived values: a cross cultural study with adolescents. Comunicación y Sociedad, 37(2), 79-99.

AIMC (2014). Audiencia de internet en el EGM: octubre-noviembre 2015. Recuperado de http://www.aimc.es/-Audiencia-de-Internet-enel-EGM-.html

AIMC (2015). Resumen general de resultados EGM: febrero a noviembre 2015. Recuperado de http://www.aimc.es/-Datos-EGM-Resumen-General-.html

Barlovento Comunicación (2013). Análisis televisivo 2013. Recuperado de http://www.barloventocomunicacion.es/images/publicaciones/ANALISIS \%20TELEVISIVO \%202013.pdf

Belmonte, J. y Guillamón, S. (2008). Coeducar la mirada frente a los estereotipos de género en televisión. Comunicar, 31, 115-120.

Bermejo, J. (2012). Los personajes y las series de ficción en la vida de los jóvenes. Revista de Estudios de Juventud, 96, 31-49.

Callejo, J. (1995). La audiencia activa. Madrid: Centro de Investigaciones Sociológicas.

Cea D’ancona, M.Á. 1996. Metodología cuantitativa: estrategias y técnicas de investigación social. Madrid: Síntesis. 
Chicharro Merayo, M. del M. (2011a). Aprendiendo de la ficción televisiva: la recepción y los efectos socializadores de Amar en tiempos revueltos. Comunicar, 36, 181-189.

Chicharro Merayo, M. del M. (2011a). Historia de la telenovela en España: aprendizaje, ensayo y apropiación de un género. Comunicación y Sociedad, 24(1), 189.

Chicharro Merayo, M. del M. (2013). Representaciones de la mujer en la ficción posfeminista: Ally McBeal, Sex and the City y Desperate Housewives. Papers: Revista de Sociología, 98, 11-31.

Dinehart, S. (2008). Transmedial play: Cognitive and cross-platform narrative. Recuperado de www.narrativedesign.org/2008/05/transmedial-play-the-aim-of-na.html

El Periódico (2015). Juego de tronos, True detective y Breaking bad las series más compradas en Amazon.es en España. Recuperado de http:// www.elperiodico.com/es/noticias/tele/juego-tronos-true-detective-breaking-bad-series-mas-compradas-amazon-espana-4783297

Falcó, L. y Díaz Aguado, M. J. (2014). Relatos adolescentes de ficción en contextos escolares. Comunicar, 42, 147-155.

Galán, E. y Del Pino, C. (2010). Jóvenes, ficción televisiva y nuevas tecnologías. Área Abierta, 25.

Gros, B. (coord.) (2004). Pantallas, juegos y educación: la alfabetización digital en la escuela. Bilbao: Desclée de Brouwer.

Hague, P. y Jackson, P. (1994). Cómo hacer una investigación de mercado. Bilbao: Ediciones Deusto.

Instituto de la Juventud (2011). Estudio de juventud 152: jóvenes y tecnologías de la información y comunicación. Madrid: Instituto de la Juventud. 
López Blasco, A., Cachón, L., Comas, D., Andreu, J., Aguinaga, J. y Navarrete, L. (2005). Informe juventud en España 2004. Madrid: Instituto de la Juventud.

López, N., Medina, E. y González, P. (2013). Los jóvenes españoles demandan una televisión con más ficción y entretenimiento. Ámbitos, Revista Internacional de Comunicación, 22. Recuperado de http:// ambitoscomunicacion.com/2013/los-jovenes-espanoles-demandan-una-television-con-mas-ficcion-y-entretenimiento/

Medina, M. (2007). Explotación económica de las series españolas en televisión. Comunicación y Sociedad, 20(1), 51-85.

Mittell, J. (2010). Television and american culture. Nueva York: Oxford University Press.

Muros, B., Aragón, Y. y Bustos, A. (2013). La ocupación del tiempo libre de jóvenes en el uso de videojuegos y redes. Comunicar, 40, 31-39.

OCDE (2010). Pisa (2009). Programa para la Evaluación Internacional de los Alumnos. Informe español. Madrid: Ministerio de Educación.

Prensky, M. (2001). Digital game bases learning. Nueva York: McGraw-Hill.

Redondo, D. (2013). Las webseries, la ficción que triunfa en internet. Recuperado de http://cadenaser.com/programa/2013/01/30/la ventana/1359505031_850215.html

Rubio, Á. y San Martín, M. Á. (2012). Subculturas juveniles: identidad, idolatrías y nuevas tendencias. Revista de Estudios de Juventud, 96, 197-213.

Salomon, G. (2000). It's not just the tool, but the educational rationale that counts Invited keynote address at the 2000 Ed-Media Meeting. Recuperado de http://www.aace.org/conf/edmedia/00/salomonkeynote.htm 
Scarpellini, P. (2013). Juego de tronos y Breaking bad, las series más pirateadas. El Mundo. Recuperado de http://www.elmundo.es/televisio $\mathrm{n} / 2013 / 12 / 29 / 52 \mathrm{c05a0bca} 47413 \mathrm{a} 708 \mathrm{~b} 456$ f.html

Scolari, C. (2009). Transmedia storytelling: Implicit consumers, narrative worlds, and branding in contemporary media production. International Journal of Communicacion, 3, 586-606. Recuperado de http://ijoc.org/index.php/ijoc/article/\%20viewFile/477/336

Siapera, E. (2004). From couch potatoes to cybernauts? The expanding notion of the audience on TV channels websites. New Media \& Society, 6, 161-167.

Strauss, A. (1987). Qualitative analysis for social scientists. Cambridge: Cambridge University Press.

Strauss, A. y Corbin, J. M. (1990). Basics of qualitative research: grounded theory procedures and techniques. Londres: Sage Publications.

Vallés, M. S. (1997). Técnicas cualitativas de investigación social. Madrid: Síntesis.

Wimmer, R. D. y Dominik, J. R. (1996). La investigación científica de los medios de comunicación: una introducción a sus métodos. Barcelona: Bosch. 